\title{
Gut Pathogens
}

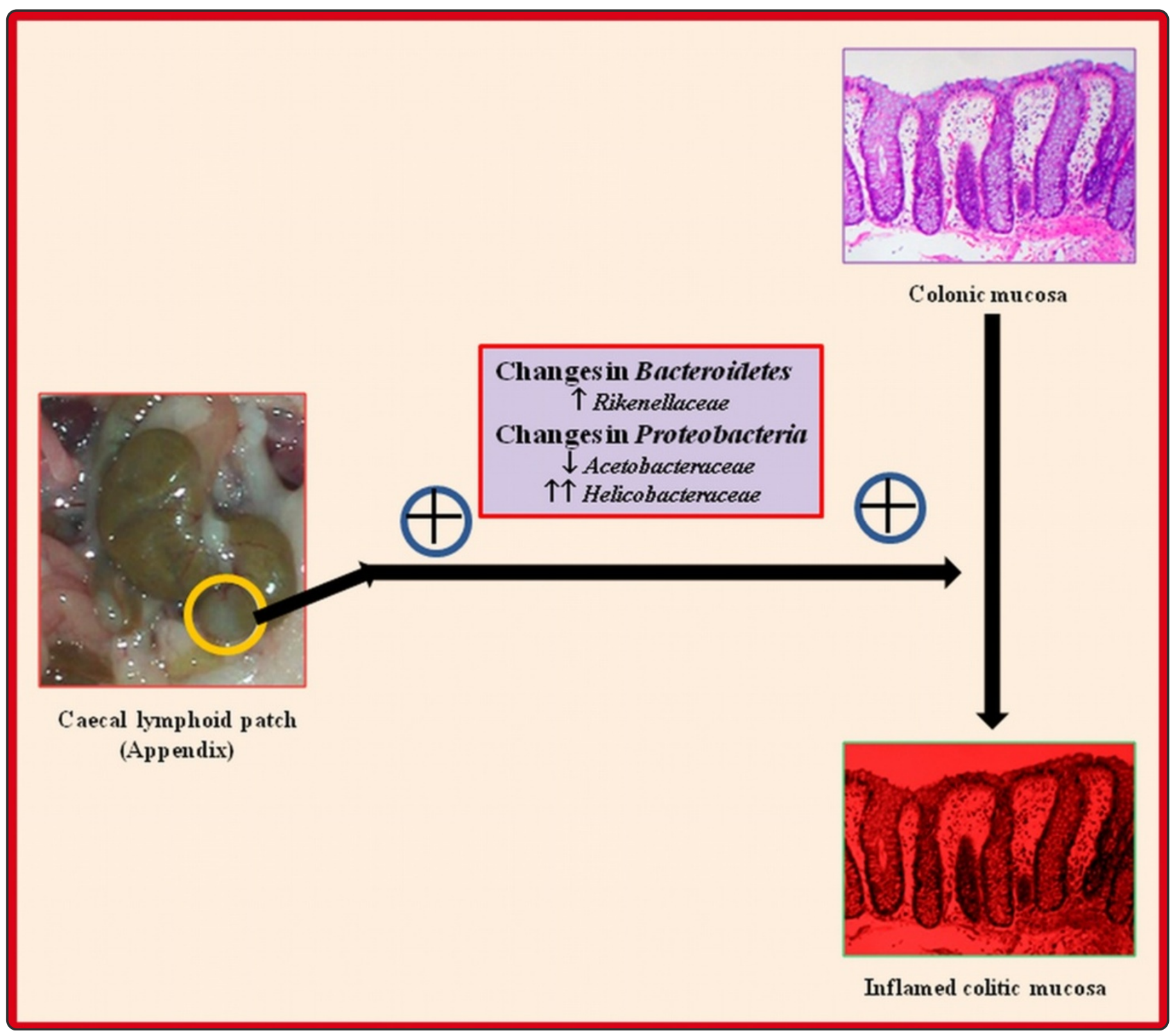

\section{The murine appendiceal microbiome is altered in spontaneous colitis and its pathological progression}

Alkadhi et al. 


\title{
The murine appendiceal microbiome is altered in spontaneous colitis and its pathological progression
}

\author{
Sultan Alkadhi', Dale Kunde ${ }^{1 *}$, Rajkumar Cheluvappa², Sarron Randall-Demllo ${ }^{1}$ and Rajaraman Eri ${ }^{*}$
}

\begin{abstract}
Background: Inflammatory bowel disease (comprising ulcerative colitis and Crohn's disease) is a multifactorial disease that is extensively associated with stool microbiome changes (dysbiosis). Appendicitis and appendectomy limits subsequent colitis, clinically, and in animal models. We wanted to examine how the appendiceal and stool microbiome fared in our spontaneous colitic Winnie $\left(\mathrm{Muc2}^{-/-}\right)$mice model.

Methods: Two C57BL/6 and 10 Winnie mice at ages 12 and 15 weeks were euthanized for stool and caecal patch samples. DNA was extracted using the QIAamp DNA Stool Mini Kit then the V1-V3 hypervariable region of the 165 rRNA gene was sequenced using the Roche/454 GS FLX + pyrosequencing instrument. A Galaxy metagenomic pipeline was used to define phyla and families at sequence similarity threshold of $\geq 80 \%$.

Results: Bacteriodetes was decreased in 15-week Winnie mice appendices compared to corresponding stool samples $(P<0.01)$. Proteobacteria was increased in appendices of Winnie mice compared to corresponding stool samples $(\mathrm{P}<0.05)$. The Bacteroidetes family Rikenellaceae could be identified only in 15 -week-old Winnie mice appendices. A higher quantity of Acetobacteraceae (Proteobacteria phylum) was present in 15-week Winnie mice when compared to 12-week Winnie mice $(P<0.01)$. Helicobacteraceae (Proteobacteria phylum), which is prominent in all Winnie mice, is absent in control mice.

Conclusions: The appendiceal dysbiosis observed in our Winnie mice is commensurate with, and adds to extant literature data. The presence of Helicobacteraceae (Proteobacteria) only in colitic Winnie mice (but not control mice) is consistent with reports of increased Helicobacter in IBD patients. Bacteroides (Bacteroidetes) decreases may be a reflection of reduced anti-inflammatory commensal species such as $B$. fragilis. Further research is warranted to expand and delineate the relationship between IBD and the appendix microbiome.
\end{abstract}

Keywords: Microbiome, Appendix, Stool, Winnie, Inflammatory bowel disease, Colitis, Proteobacteria, Bacteroidetes

\section{Background}

Inflammatory bowel disease (IBD) comprises ulcerative colitis (UC) and Crohn's disease (CD). It has a relapsing and remitting clinical course, and is characterized by chronic intestinal inflammation with abdominal pain and intestinal dysfunction. UC and CD differ in extent, localization, and inflammatory mediator profiles [1]. The etiology of IBD is unknown, but is thought to result from complex interactions between host and environmental

\footnotetext{
*Correspondence: dkunde@utas.edu.au; rderi@utas.edu.au

'Mucosal Biology Laboratory, School of School of Health Sciences, University of Tasmania, Launceston, TAS, Australia

Full list of author information is available at the end of the article
}

components like diet, standard of living, and antibiotic use [2]. IBD is on the rise in developed countries, the latest incidence in Australia being 29.6 per 100,000 [3]. IBD poses a significant economic and public health burden [4].

Gastrointestinal flora (intestinal microbiome) is crucial for human health, mediating important functions in metabolism and immunity [5]. There is a glut of evidence that link the intestinal microbiome to the pathogenesis of IBD [6]. The human microbiome is most concentrated in the colon $\left(10^{12}\right.$ cells per gram), which is the region most affected in IBD [7]. Manifold studies link IBD with antigen-sensing and intestinal innate immunity genes such 
as NOD2 and ATG16L1 [8]. Importantly, compositional changes in the intestinal micriobiota (dysbiosis) are significant features of bowel diseases [9]. The correlation between dysbiosis and IBD is not completely understood, and human studies involve confounding variables on bacterial composition, such as antibiotic use [10]. In contrast, animal models of IBD enable the study of the gut microbiome while reducing environmental influence [11]. The Winnie mouse strain has missense mutations in the mucin $M u c 2$ gene that alters the intestinal barrier, and results in "spontaneous" colitis, characterized by intestinal inflammation and activation of the IL-23/Th17 pathway [12]. Winnie mice are more vulnerable to intestinal antigens due to defects in Paneth and goblet cells [13], and present with chronologically progressive IBD symptoms such as bloody stools, diarrhoea, and weight loss [12]. All Winnie mice (100\%) develop mild spontaneous distal intestinal inflammation by the time they are 6 weeks old [14]. Colitic signs and symptoms become progressively worse chronologically. Colitis is therefore significantly worse in 15-week Winnie mice, when compared to 12-week Winnie mice. Corresponding commensurate histopathological findings have already been published [14].

A succinct summary and critical appraisal of more than a dozen studies by Koutroubakis et al. [15], show that appendicitis and appendectomy (AA) prevents or significantly ameliorates ulcerative colitis. In the mouse, the caecal lymphoid patch (Figure 1) is the rough equivalent of the human appendix. In Figure 1, this is the pale milky-white area encircled with a ring. AA in the most proximal colon substantially curbs $\mathrm{T}$ helper 17 cell -recruitment, -differentiation, -activation, and -effector (interleukin) expression in the most distal colon; thereby contributing significantly to suppressing Th17 pathwaymediated immunopathology in TNBS-colitis [16]. AA curbs autophagy [8], potentially contributing to suppression of autophagy-mediated immunopathology in colitis.

The appendix cannot be considered a "vestigial" organ "anymore". Mouse models of spontaneous colitis have shown a significant role for the appendix in the adaptive immune response [17]. Appendectomy in these models also markedly reduced the risk for colitis development [17]. Several hypotheses exist explain this relationship, and, as more evidence endorses its important role in mucosal immunity [18]. The 2 most plausible explanations are as follows. The appendix may initiate an aberrant immune response against the gut microbiome, predisposing to IBD [19]. Alternatively, appendicitis and appendectomy may induce microbiota changes and/ or major immunological changes in the distal colon which protect against colitis development $[8,16]$.

Most intestinal flora is anaerobic, and difficult to identify using culture-dependent methods [20]. However, next

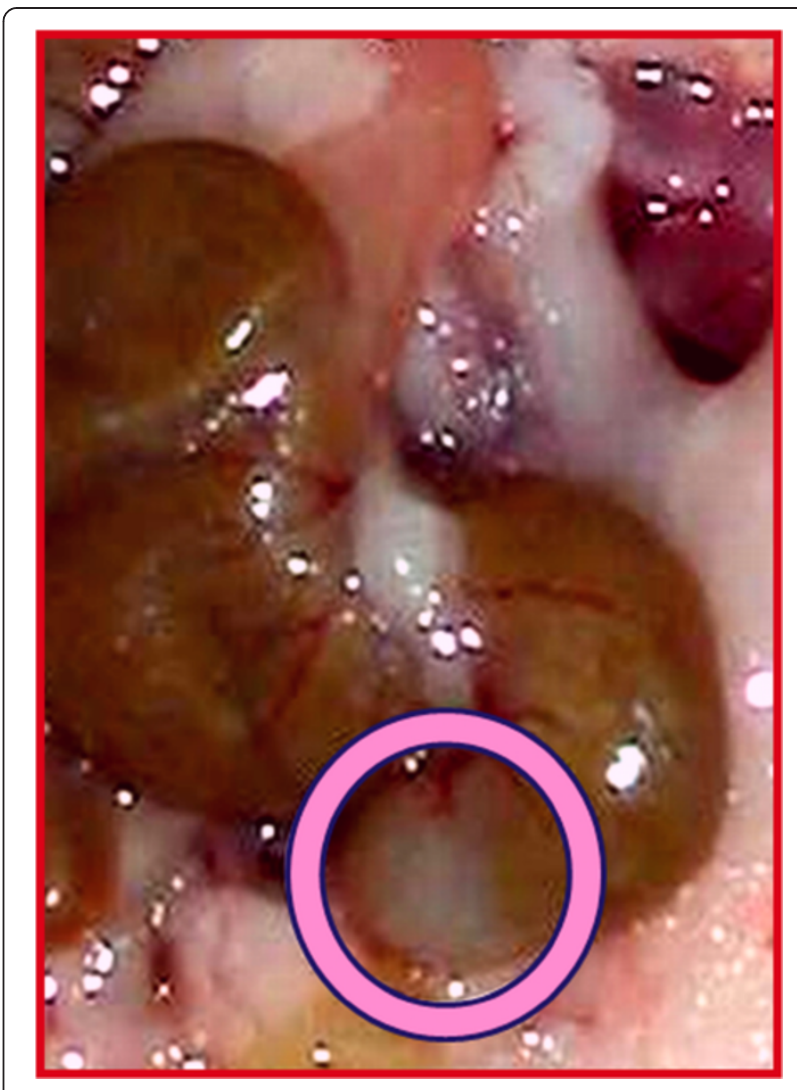

Figure 1 The mouse caecal lymphoid patch (appendix). Normal

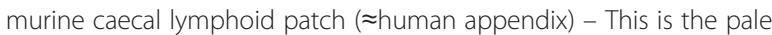
milky-white area encircled with a ring. [License number to reproduce image from John Wiley and Sons - 3415650102997]

generation sequencing methods have enabled the highthroughput phylogenetic study of microbial populations from multiple samples in parallel [21]. The bacterial genome is assembled by amplification of fragments of the conserved 16S rRNA gene [22]. Hyper-variable regions within $16 \mathrm{~S}$ rRNA are utilised to characterize different taxonomic levels [23]. In this study, we sought to investigate the microbiome signatures of Winnie mice in different stages of colitis development (at ages 12 and 15 weeks) and compare those against the control strain (C57BL/6). Microbiome alterations are expected between mice strains, as well as before and after inflammation. The rationale of our study was not only to determine what changes exist between a "normal" mouse strain, and a "spontaneously colitic" (Winnie) strain; but also to determine what bacteria were present at each stage of inflammation progression. These experiments will shed more light on the pathogenetic nuances of IBD. We compared stool and appendix phyla, as well as more intricate differences at the family level. Herewith, we posit the differences between the appendix and colon (stool), in normal controls and colitic Winnie mice. 


\section{Results and discussion Results}

Microbiome signature in winnie and $\mathrm{C} 57 \mathrm{BL} / 6$

The Bacteriodetes phylum is the most abundant phylum in appendix and stool samples from both C57BL/6 and Winnie mice at both time-points (Figure 2). Bacteriodetes was significantly decreased $(\mathrm{P}<0.01)$ in 15 -week Winnie appendix samples compared to 15-week Winnie stool samples (Figure 3B). The Proteobacteria phylum was significantly more $(\mathrm{P}<0.05)$ in appendix samples belonging to both time-points in Winnie mice (12 weeks and 15 weeks), when each was compared to stool samples (Figure 3D). No significant differences were observed between the microbiome signatures of Winnie stool samples. No significant differences were observed between the microbiome signatures of Winnie appendix samples.
Family-level bacteriodetes signatures in appendices Family analyses of appendiceal Bacteriodetes phylum reveal no significant differences in family breakdown. Bacteroidaceae is the dominant (>90\%) family in the appendices of both mouse strains, at both time-points (Figure 4A). There are no statistically significant differences in the constituents and proportion of Bacteroidetes families in appendices (Figure 4A). However, the Bacteroidetes family Rikenellaceae could be identified only in 15-week-old Winnie mice appendices (Figure 4B).

\section{Family-level proteobacteria signatures in appendices}

Family analyses of appendiceal Proteobacteria phylum reveal significant Acetobacteraceae increases $(\mathrm{P}<0.05)$ in 15 -week Winnie mice when compared to 12 -week Winnie mice (Figure 5A). Helicobacteraceae, which is prominent

\section{BL/6 - Appendix}

$\square$ Actinobacteria $\square$ Bacteroidetes $\square$ Firmicutes $\square$ Prote obacteria

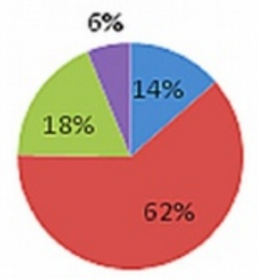

\section{2wk Winnie - Appendix}

घActinobacteria $\square$ Bacteroidetes $\square$ Firmicutes $\square$ Prote obacteria

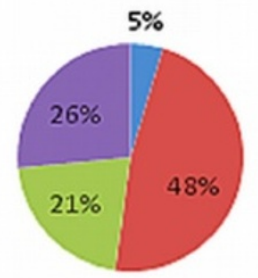

\section{5wk Winnie - Appendix}

$\square$ Actinobacteria $\square$ Bacteroidetes $\square$ Firmicutes $\square$ Prote obacte ria

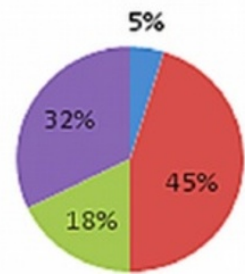

Figure 2 Overview of most common bacterial colonies in mouse appendices and stool. The Bacteriodetes phylum is the most abundant phylum in appendix and stool samples, from both C57BL/6 and Winnie mice. The Proteobacteria phylum is second most abundant in stool samples from both C57BL/6 and Winnie mice. The number of samples varied from 2-5 for each group.

\section{BL/6 - Stool}

aActinobacteria $\square$ Bacteroidetes $\square$ Firmicutes $\square$ Prote obacteria

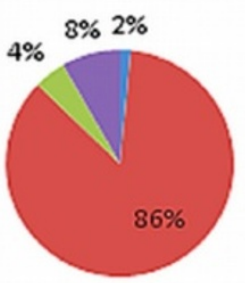

\section{2wk Winnie - Stool}

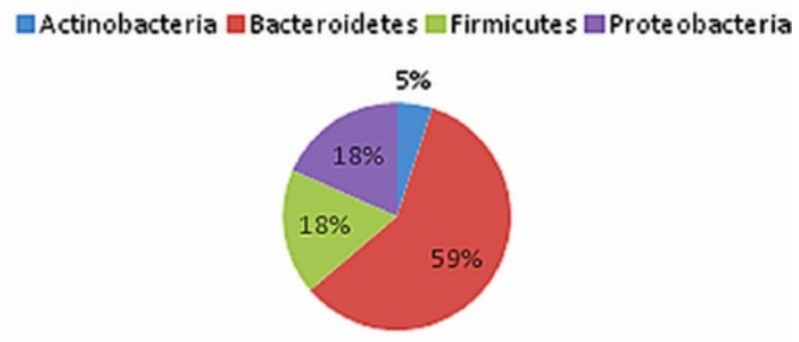

15wk Winnie -Stool
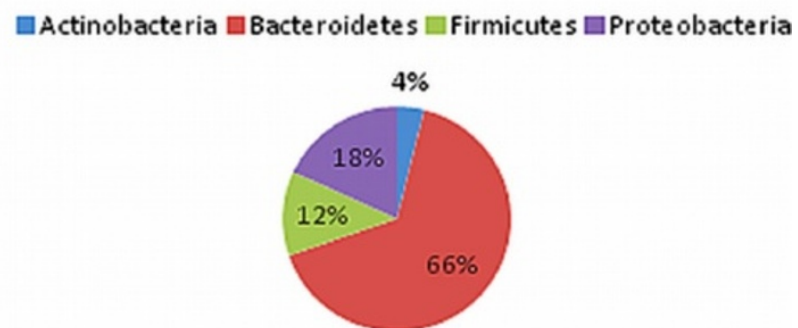


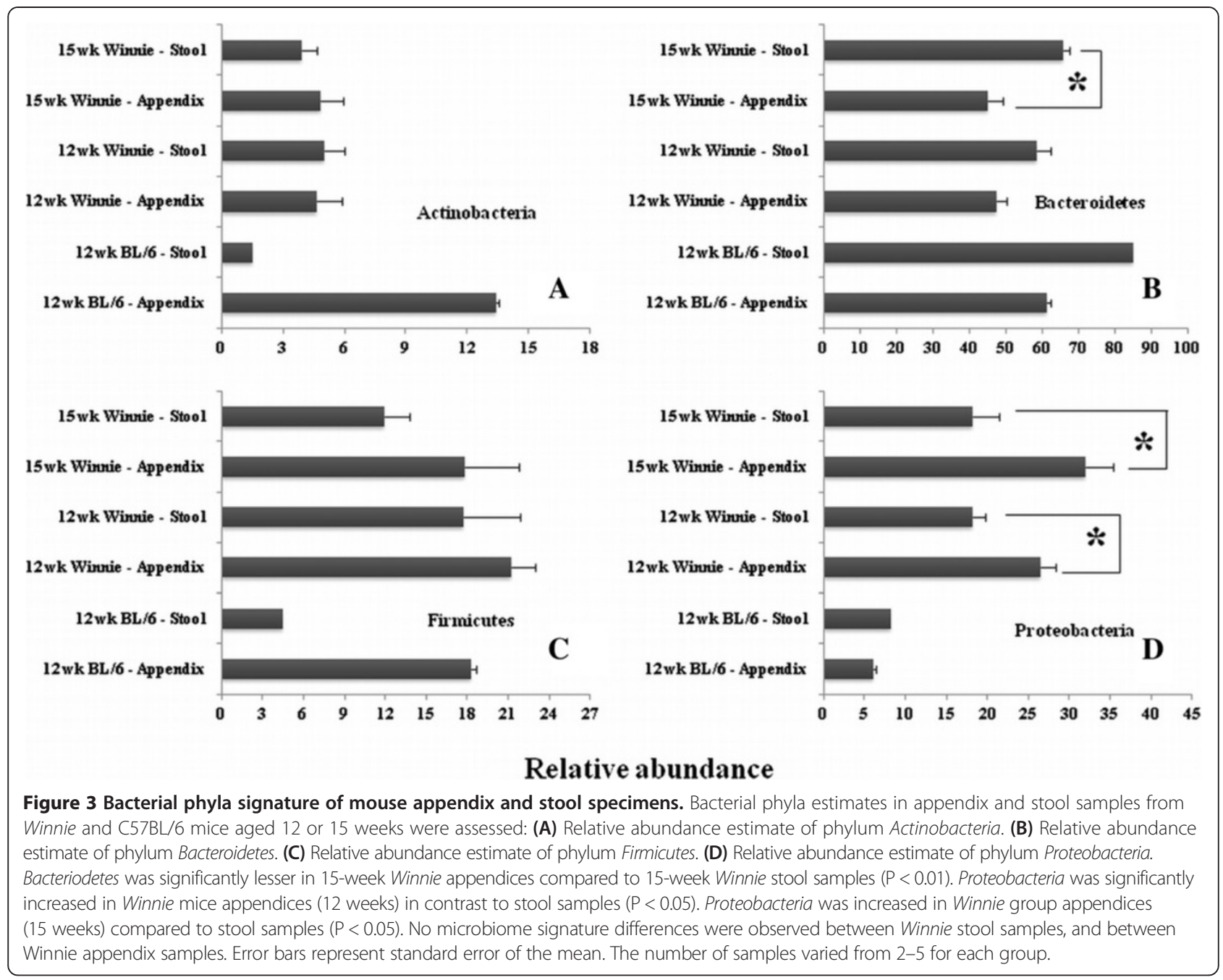

in Winnie mice at both time-points, are not represented in C57BL/6 (Figure 5B). The Proteobacteria families Rhizobiaceae, Pasteurellaceae, Xanthomonadaceae, Vibrionaceae, Sphingomonadaceae, Bartonellaceae, Pseudomonadaceae, and Campylobacteraceae which were present in traces in 12-week Winnie mice appendices, disappear at the 15-week time-point (Figure 5B).

\section{Discussion}

The human vermiform appendix is commonly, but wrongly perceived to be a vestigial organ, despite its abundant lymphoid tissue, and despite the fact that appendicitis is the most common abdominal surgery requiring hospitalization. Anatomically, owing to its proximity to the caecal segment of the large intestine, it is perpetually exposed to and gastrointestinal microbiota. As the murine caecal lymphoid patch (Figure 1) is the equivalent of human appendix, this study investigated the microbial content differences of the caecal patch to the rest of colon (via stool contents).
Bacteriodetes was decreased in 15-week Winnie mice appendices compared to corresponding stool samples (Figure 3B). Proteobacteria increased in appendices of Winnie mice (12 weeks and 15 weeks), when each was compared to corresponding stool samples (Figure 3D). The Bacteroidetes family Rikenellaceae could be identified only in 15-week-old Winnie mice appendices (Figure 4B, Figure 6). Significantly more Acetobacteraceae (Proteobacteria phylum) was present in 15-week Winnie mice when compared to 12-week Winnie mice (Figure 5A, Figure 6). Helicobacteraceae (Proteobacteria phylum), prominent in all Winnie mice, is absent in C57BL/6 control mice (Figure 5B, Figure 6).

Intestinal biopsies from IBD patients display marked aberrations in the microbiome signature [24], inclusive of its Proteobacteria and Bacteriodetes constituents [25]. Surgical samples from IBD patients show reduced Bacteroidetes load compared to healthy patients [26]. Colonic biopsies show significantly more Proteobacteria in IBD patients [27]. Bacteroidetes species are an 


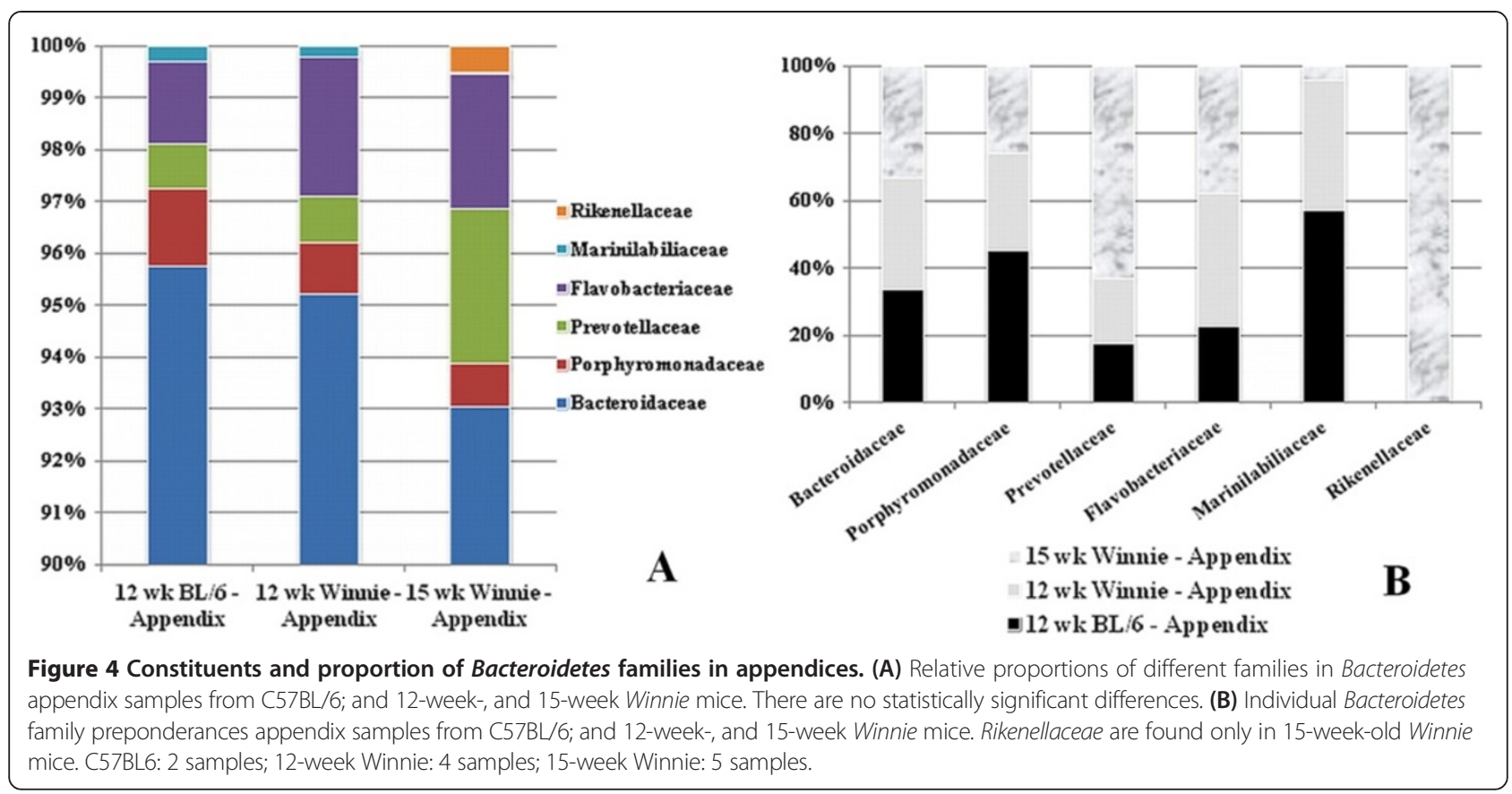

important source of short chain fatty acids to the intestinal epithelia [28]. In addition, Bacteroidetes regulate the generation of colonic regulatory $\mathrm{T}$ cells, which maintain immunological tolerance against the gut microbiome [29]. Specifically, capsular polysaccharide A from Bacteroides fragilis stimulates colonic regulatory $\mathrm{T}$ cells enhances the release of the anti-inflammatory cytokine IL-10 [30].

Proteobacteria levels are higher in IBD patients [31]. Multiple classes of Proteobacteria are associated with IBD including Deltaproteobacteria, which include sulphur-reducing

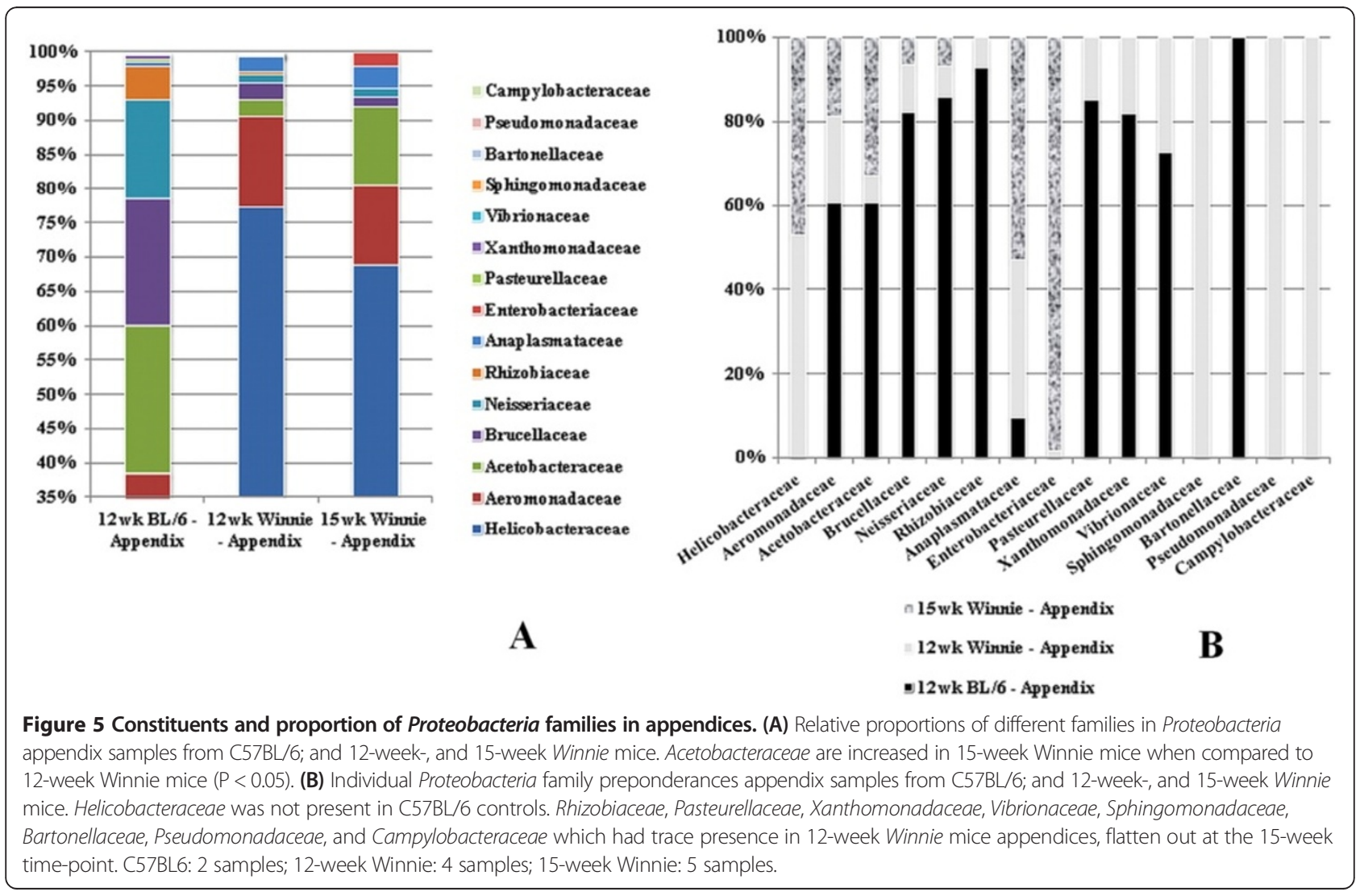




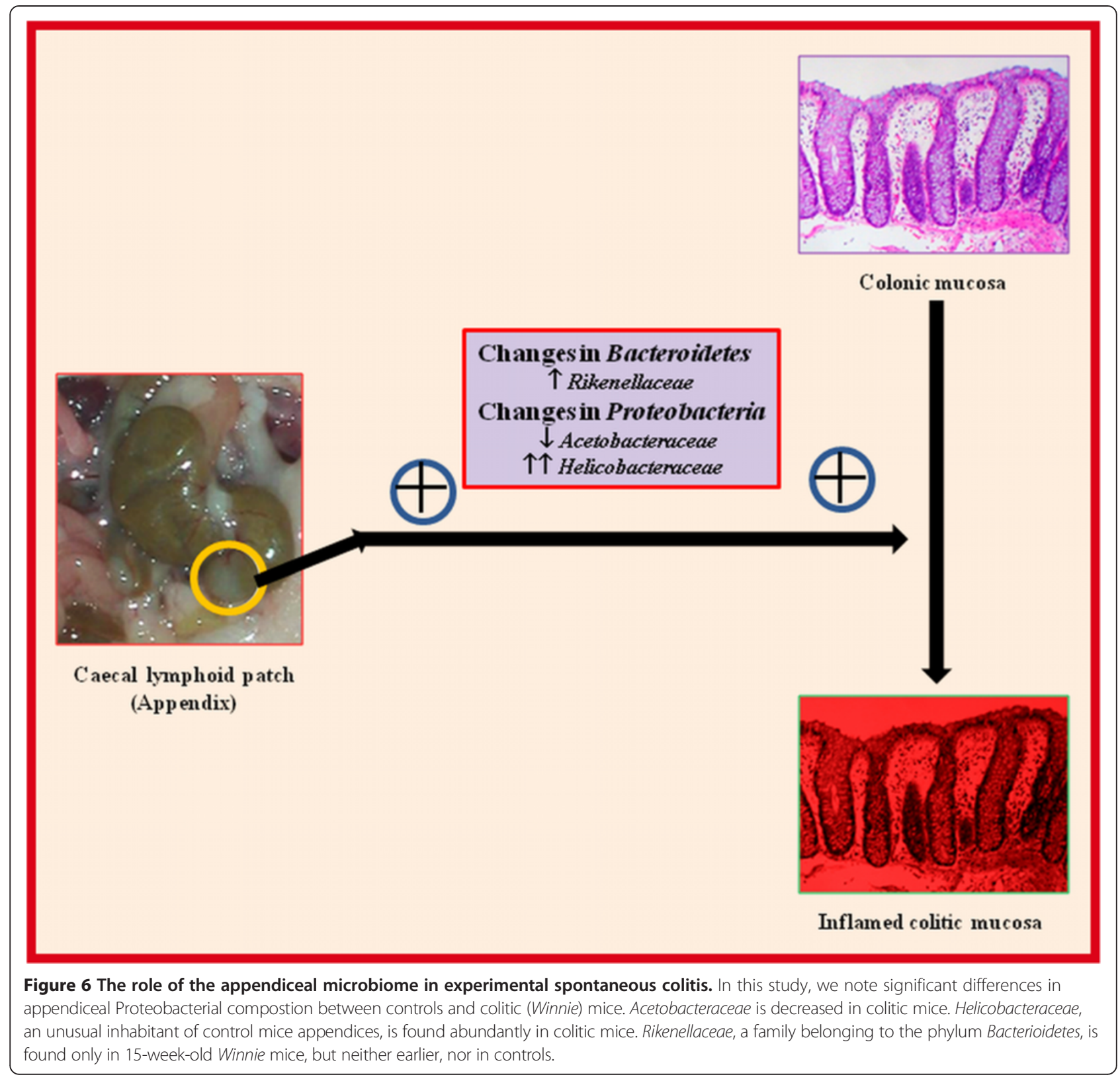

bacteria [32]. Increased sulphide damages intestinal walls [33] and inhibits butyrate oxidation [34]. More importantly, Helicobacter species, which was represented in Winnie mice but not in C57BL/6 (Figure 5B, Figure 6), is strongly associated with clinical IBD (UC > CD) [35]. The increase in Helicobacteraceae in IBD patients is not due to Helicobacter pylori infection, as Helicobacteraceae is prominent in colonic but not gastric mucosa [36].

Limitations of our study include small sample sizes, and methodological differences (with other studies) in DNA extraction/sequencing, which may hypothetically impart an element of inconsistency. Firstly, the QIAamp DNA Stool Mini kit we used relies on enzymatic lysis, and produces substantially less DNA yield, compared to extraction methods involving vigorous mechanical lysis [37], or bead-beating [38]. This may have a disproportionate impact on specific bacterial groups which are tougher to lyse owing to stronger cell walls [39]. In addition, pyrosequencing can be biased by selection of the primer pair, and amplifying different $16 \mathrm{~S}$ rRNA hyper-variable regions may enhance sequencing coverage [40].

Our study suggests an association or a pathogenic role for the appendix and its flora in colitic predisposition. Further characterisation of chronological differences in inflammation progression, as well as the magnitude of colitis pathology; would divulge whether our observed 
microbiome changes indicate association or causality. Dysbiosis within the appendix (caecal patch) of our colitis model was significantly more than within stool samples, especially in older (15-week) Winnie mice, where intestinal epithelial defects become pronounced [41]. It is not clear whether dysbiosis is a cause or consequence of intestinal inflammation [42]. However, it is less likely to be the former, owing to the therapeutic benefit easily conferred by gut microbiome manipulation [10]. Reversing the dysbiotic-inflammatory positive feedback loop with faecal microbiota transplantation has produced positive results in recurrent Clostridium difficile-associated disease (CDAD) [43]. While the appendix might promote C. difficile infection [44], retrospective studies in humans show a protective role against CDAD recurrence [45]. Additional research in experimental models is needed to explain these discrepancies.

\section{Conclusions}

The correlation between dysbiosis and IBD is incompletely understood. Our Winnie mouse strain has an altered intestinal barrier, resulting in spontaneous colitis, characterized by intestinal ulceration and inflammation. The appendiceal dysbiosis observed in our colitic Winnie mice is commensurate with, and adds to extant literature data. The presence of Helicobacteraceae (Proteobacteria) only in colitic Winnie mice (but not control mice) is consistent with reports of increased Helicobacter in IBD patients. Bacteroides (Bacteroidetes) decreases may be a reflection of reduced anti-inflammatory commensal species such as B. fragilis. Further research is warranted to expand and delineate the relationship between IBD and the appendix microbiome. Despite inherent differences between mouse and human gut flora, this study using our Winnie colitis model will vastly increase our understanding of IBD pathogenesis.

\section{Methods \\ Mice}

Two C57BL/6 and 18 Winnie mice were purchased from the Animal Resource Centre, Australia. Owing to discrepancies in the supply of mice strains, there were mild differences in the number of animals in each experimental group. The mice were bred in a conventional clean Helicobacter hepaticus - free animal facility used for all the experiments, which were conducted under the directions and approval of the animal ethics committee of the University of Queensland.

\section{Caecal patch (appendix) excision and DNA extraction}

Caecal patch was identified as a whitish-patch segment right at the end portion away from the colonic side (Figure 1). About $1 \mathrm{~cm}$ excision was made and the sample with contents was immediately snap-frozen for further DNA processing. In the laboratory, stool material was scraped and DNA extracted using QIAamp DNA mini kit (Qiagen, Hilden, Germany). Bacterial DNA content was confirmed with bacterial $16 \mathrm{~s}$ rRNA broad-range primers.

\section{DNA extraction}

Mice were euthanized at ages 12 and 15 weeks and appendix and stool samples were immediately frozen and stored at $-80^{\circ} \mathrm{C}$. DNA was extracted using the QIAamp DNA Stool Mini Kit (Qiagen, Hilden, GER), according to manufacturer's instructions then stored in $-20^{\circ} \mathrm{C}$. Bacterial DNA content was confirmed using the A260/A280 ratio and real-time PCR of $16 \mathrm{~S}$ rRNA using broad-range primers as described previously [46] on the iQ5 real-time PCR system (Bio-RAD Laboratories, CA, USA).

\section{DNA sequencing and metagenomic analysis}

Sequencing amplicons were generated for the V1-V3 hypervariable region of the $16 \mathrm{~S}$ rRNA gene using the 27 F-519R primers and DNA was sequenced using the Roche GS FLX + 454-pyrosequencing platform at the Australian Genome Research Facility. Profiling of the microbiome was performed using the metagenomic tools available in the Galaxy Public Server [47] following the metagenomic pipeline described by Kasakovsky Pond et al. [48]. Briefly, sequences were filtered to exclude reads with a quality score $<20$ and a contiguous length $<250 \mathrm{bp}$. Sequences were compared to the WGS database (28jan2013) using MegaBLAST z [49] and after removing hits with $<50 \%$ coverage, Operational Taxonomic Units (OTU) were designated based on $80 \%$ similarity and identity defined to the lowest taxonomic rank of kingdom.

\section{Statistical analysis}

Since our results could not form a normal distribution due to the small sample size, we used the non-parametric Mann-Whitney U-test. Graphs were generated with Prism v6 (GraphPad Software, CA, USA).

\section{Abbreviations \\ IBD: Inflammatory bowel disease; CD: Crohn's disease; UC: Ulcerative colitis; NOD2: Nucleotide-binding oligomerization domain-containing protein 2; ATG16L1: Autophagy related 16-like 1; IL-23: Interleukin-23; Th17: T helper 17; AA: Appendicitis and appendectomy; $16 \mathrm{~S}$ rRNA: $16 \mathrm{~S}$ ribosomal RNA: TNBS: 2,4,6-Trinitrobenzenesulfonic acid; OTU: Operational taxonomic unit.}

\section{Competing interest}

The authors declare that they have no competing interests.

\section{Author contributions}

RE and DK - Conception and design; SA, DK, SR-D - Research work; SA, RC, DK, SR-D, RE - Figure preparation \& Manuscript writing. All authors read and approved the final manuscript.

\section{Acknowledgements}

National Health and Medical Research Council (NHMRC) Grant Number 604304. 


\section{Author details}

'Mucosal Biology Laboratory, School of School of Health Sciences, University of Tasmania, Launceston, TAS, Australia. ${ }^{2}$ Department of Medicine, St. George Clinical School, University of New South Wales, Sydney, NSW, Australia.

Received: 28 May 2014 Accepted: 13 June 2014

Published: 21 June 2014

\section{References}

1. Lomer MCE: Dietary and nutritional considerations for inflammatory bowel disease. Proc Nutr Soc 2011, 70:329-335.

2. Jaeger $\mathrm{S}$, Stange EF, Wehkamp J: Inflammatory bowel disease: an impaired barrier disease. Langenbecks Arch Surg 2013, 398:1-12.

3. Wilson J, Hair C, Knight R, Catto-Smith A, Bell S, Kamm M, Desmond P, McNeil J, Connell W: High incidence of inflammatory bowel disease in Australia: a prospective population-based Australian incidence study. Inflamm Bowel Dis 2010, 16:1550-1556.

4. Morrison G, Headon B, Gibson P: Update in inflammatory bowel disease. Aust Fam Physician 2009, 38:956-961.

5. Proal AD, Albert PJ, Marshall TG: The human microbiome and autoimmunity. Curr Opin Rheumatol 2013, 25:234-240.

6. Backhed F, Ley RE, Sonnenburg JL, Peterson DA, Gordon Jl: Host-bacterial mutualism in the human intestine. Science (New York, NY) 2005, 307:1915-1920.

7. Vipperla K, O'Keefe SJ: The Microbiota and Its Metabolites in Colonic Mucosal Health and Cancer Risk. Nutr Clin Pract 2012, 27:624-635.

8. Cheluvappa R, Luo AS, Grimm MC: Autophagy suppression by appendicitis and appendectomy protects against colitis. Inflamm Bowel Dis 2014, 20:847-855.

9. Brown K, DeCoffe D, Molcan E, Gibson DL: Diet-Induced Dysbiosis of the Intestinal Microbiota and the Effects on Immunity and Disease. Nutrients 2012, 4:1095-1119

10. Sartor RB: Therapeutic manipulation of the enteric microflora in inflammatory bowel diseases: antibiotics, probiotics, and prebiotics. Gastroenterology 2004, 126:1620-1633.

11. Kostic AD, Howitt MR, Garrett WS: Exploring host-microbiota interactions in animal models and humans. Genes Dev 2013, 27:701-718.

12. Eri RD, Adams RJ, Tran TV, Tong H, Das I, Roche DK, Oancea I, Png CW, Jeffery PL, Radford-Smith GL, Cook MC, Florin TH, McGuckin MA: An intestinal epithelial defect conferring ER stress results in inflammation involving both innate and adaptive immunity. Mucosal Immunol 2011, 4:354-364.

13. McGuckin MA, Eri RD, Das I, Lourie R, Florin TH: ER stress and the unfolded protein response in intestinal inflammation. Am J Physiol Gastrointest Liver Physiol 2010, 298:G820-G832.

14. Heazlewood CK, Cook MC, Eri R, Price GR, Tauro SB, Taupin D, Thornton DJ, Png CW, Crockford TL, Cornall RJ, Adams R, Kato M, Nelms KA, Hong NA, Florin TH, Goodnow CC, McGuckin MA: Aberrant mucin assembly in mice causes endoplasmic reticulum stress and spontaneous inflammation resembling ulcerative colitis. PLoS Med 2008, 5:e54.

15. Koutroubakis IE, Vlachonikolis IG, Kouroumalis EA: Role of appendicitis and appendectomy in the pathogenesis of ulcerative colitis: a critical review. Inflamm Bowel Dis 2002, 8:277-286.

16. Cheluvappa R, Luo AS, Grimm MC: T helper type 17 pathway suppression by appendicitis and appendectomy protects against colitis. Clin Exp Immunol 2014, 175:316-322.

17. Mizoguchi A, Mizoguchi E, Chiba C, Bhan AK: Role of appendix in the development of inflammatory bowel disease in TCR-alpha mutant mice. J Exp Med 1996, 184:707-715.

18. Matsushita M, Takakuwa H, Matsubayashi Y, Nishio A, Ikehara S, Okazaki K: Appendix is a priming site in the development of ulcerative colitis. World J Gastroenterol 2005, 11:4869-4874.

19. Krieglstein CF, Cerwinka WH, Laroux FS, Grisham MB, Schurmann G, Bruwer $M$, Granger DN: Role of appendix and spleen in experimental colitis. J Surg Res 2001, 101:166-175.

20. Suau A, Bonnet R, Sutren M, Godon JJ, Gibson GR, Collins MD, Dore J: Direct analysis of genes encoding $16 \mathrm{~S}$ rRNA from complex communities reveals many novel molecular species within the human gut. Appl Environ Microbiol 1999, 65:4799-4807.

21. Schloss PD, Handelsman J: Metagenomics for studying unculturable microorganisms: cutting the Gordian knot. Genome Biol 2005, 6:229.
22. Frank DN, Pace NR: Gastrointestinal microbiology enters the metagenomics era. Curr Opin Gastroenterol 2008, 24:4-10.

23. Langille MGI, Zaneveld J, Caporaso JG, McDonald D, Knights D, Reyes JA, Clemente JC, Burkepile DE, Thurber RLV, Knight R, Beiko RG, Huttenhower C: Predictive functional profiling of microbial communities using 165 rRNA marker gene sequences. Nat Biotechnol 2013, 31:814.

24. Fite A, Macfarlane S, Furrie E, Bahrami B, Cummings JH, Steinke DT, Macfarlane GT: Longitudinal Analyses of Gut Mucosal Microbiotas in Ulcerative Colitis in Relation to Patient Age and Disease Severity and Duration. J Clin Microbiol 2013, 51:849-856.

25. Gophna U, Sommerfeld K, Gophna S, Doolittle WF, van Zanten S: Inerences between tissue-associated intestinal microfloras of patients with Crohn's disease and ulcerative colitis. J Clin Microbiol 2006, 44:4136-4141.

26. Frank DN, Amand ALS, Feldman RA, Boedeker EC, Harpaz N, Pace NR: Molecular-phylogenetic characterization of microbial community imbalances in human inflammatory bowel diseases. Proc Natl Acad Sci U S A 2007, 104:13780-13785.

27. Lepage P, Hasler R, Spehlmann ME, Rehman A, Zvirbliene A, Begun A, Ott S, Kupcinskas L, Dore J, Raedler A, Schreiber S: Twin Study Indicates Loss of Interaction Between Microbiota and Mucosa of Patients With Ulcerative Colitis. Gastroenterology 2011, 141:227-236.

28. Fava F, Danese S: Intestinal microbiota in inflammatory bowel disease: friend of foe? World I Gastroenterol 2011, 17:557-566.

29. Lathrop SK, Bloom SM, Rao SM, Nutsch K, Lio CW, Santacruz N, Peterson DA, Stappenbeck TS, Hsieh CS: Peripheral education of the immune system by colonic commensal microbiota. Nature 2011, 478:250-252.

30. Mazmanian SK, Round JL, Kasper DL: A microbial symbiosis factor prevents intestinal inflammatory disease. Nature 2008, 453:620-625.

31. Mukhopadhya I, Hansen R, El-Omar EM, Hold GL: IBD-what role do Proteobacteria play? Nat Rev Gastroenterol Hepatol 2012, 9:219-230

32. Loubinoux J, Bronowicki JP, Pereira IA, Mougenel JL, Faou AE: Sulfate-reducing bacteria in human feces and their association with inflammatory bowel diseases. FEMS Microbiol Ecol 2002, 40:107-112.

33. Pitcher MC, Cummings JH: Hydrogen sulphide: a bacterial toxin in ulcerative colitis? Gut 1996, 39:1-4

34. Pitcher MC, Beatty ER, Cummings JH: The contribution of sulphate reducing bacteria and 5-aminosalicylic acid to faecal sulphide in patients with ulcerative colitis. Gut 2000, 46:64-72.

35. Thomson JM, Hansen R, Berry SH, Hope ME, Murray GI, Mukhopadhya I, McLean MH, Shen Z, Fox JG, El-Omar E, Hold GL: Enterohepatic helicobacter in ulcerative colitis: potential pathogenic entities? PLoS One 2011, 6:e17184

36. Zhang L, Day A, McKenzie G, Mitchell H: Nongastric Helicobacter species detected in the intestinal tract of children. J Clin Microbiol 2006, 44:2276-2279.

37. Maukonen J, Simoes C, Saarela M: The currently used commercial DNA-extraction methods give different results of clostridial and actinobacterial populations derived from human fecal samples. FEMS Microbiol Ecol 2012, 79:697-708.

38. Ariefdjohan MW, Savaiano DA, Nakatsu CH: Comparison of DNA extraction kits for PCR-DGGE analysis of human intestinal microbial communities from fecal specimens. Nutr J 2010, 9:23.

39. Claassen S, du Toit E, Kaba M, Moodley C, Zar HJ, Nicol MP: A comparison of the efficiency of five different commercial DNA extraction kits for extraction of DNA from faecal samples. J Microbiol Methods 2013, 94:103-110.

40. Li E, Hamm CM, Gulati AS, Sartor RB, Chen H, Wu X, Zhang T, Rohlf FJ, Zhu W, Gu C, Robertson CE, Pace NR, Boedeker EC, Harpaz N, Yuan J, Weinstock GM, Sodergren E, Frank DN: nflammatory Bowel Diseases Phenotype, C. difficile and NOD2 Genotype Are Associated with Shifts in Human lleum Associated Microbial Composition. PLoS One 2012, 7:e26284.

41. Van der Sluis M, De Koning BA, De Bruijn AC, Velcich A, Meijerink JP, Van Goudoever JB, Buller HA, Dekker J, Van Seuningen I, Renes IB, Einerhand AW: Muc2-deficient mice spontaneously develop colitis, indicating that MUC2 is critical for colonic protection. Gastroenterology 2006, 131:117-129.

42. Nagalingam NA, Lynch SV: Role of the microbiota in inflammatory bowel diseases. Inflamm Bowel Dis 2012, 18:968-984.

43. Landy J, Al-Hassi HO, McLaughlin SD, Walker AW, Ciclitira PJ, Nicholls RJ, Clark SK, Hart AL: Review article: faecal transplantation therapy for gastrointestinal disease. Aliment Pharmacol Ther 2011, 34:409-415.

44. Merchant R, Mower WR, Ourian A, Abrahamian FM, Moran GJ, Krishnadasan A, Talan DA: Association Between Appendectomy and Clostridium difficile Infection. J clinical Med Res 2012, 4:17-19. 
45. Sanders NL, Bollinger RR, Lee R, Thomas S, Parker W: Appendectomy and Clostridium difficile colitis: Relationships revealed by clinical observations and immunology. World J Gastroenterol 2013, 19:5607-5614.

46. Kommedal O, Simmon K, Karaca D, Langeland N, Wiker HG: Dual priming oligonucleotides for broad-range amplification of the bacterial $16 \mathrm{~S}$ rRNA gene directly from human clinical specimens. J Clin Microbiol 2012, 50:1289-1294.

47. Goecks J, Nekrutenko A, Taylor J, Galaxy T: Galaxy: a comprehensive approach for supporting accessible, reproducible, and transparent computational research in the life sciences. Genome Biol 2010, 11:R86

48. Kasokovsky Pond S, Wadhawan S, Chiaromonte F, Ananda G, Chung W, Taylor J, Nekrutenko A, Galaxy T: Windshield splatter analysis with thye Galaxy metagenomic pipeline. Genome Res 2009, 19:2144-2153.

49. Zhang Z, Schwartz S, Wagner L, Miller W: A greedy algorithm for aligning DNA sequences. J Comput Biol 2000, 7:203-214.

doi:10.1186/1757-4749-6-25

Cite this article as: Alkadhi et al:: The murine appendiceal microbiome is altered in spontaneous colitis and its pathological progression.

Gut Pathogens 2014 6:25.

\section{Submit your next manuscript to BioMed Central and take full advantage of:}

- Convenient online submission

- Thorough peer review

- No space constraints or color figure charges

- Immediate publication on acceptance

- Inclusion in PubMed, CAS, Scopus and Google Scholar

- Research which is freely available for redistribution 